\title{
LA PERIFERIA URBANA DE SEVILLA EN UN PLANO INÉDITO DE MANUEL SPÍNOLA (1827)
}

\author{
Tomás Díaz Zamudio \\ Escuela Técnica Superior de Arquitectura. Universidad de Sevilla \\ diazzamudio@us.es \\ ORCID iD: https://orcid.org/0000-0001-6973-2347 \\ Antonio Gámiz Gordo \\ Escuela Técnica Superior de Arquitectura. Universidad de Sevilla \\ antoniogg@us.es \\ ORCID iD: https://orcid.org/0000-0001-6188-3167 \\ Magdalena Valor Piechotta \\ Facultad de Geografía e Historia. Universidad de Sevilla \\ magdalen@us.es \\ ORCID iD: https://orcid.org/0000-0003-4597-1663
}

Recibido: : 15/03/2017; Aceptado: 22/02/2019.

Cómo citar este artículo/Citation: Díaz Zamudio, T., Gámiz Gordo, A. y Valor Piechotta, M. (2019). La periferia urbana de Sevilla en un plano inédito de Manuel Spínola (1827). Estudios Geográficos, 80 (286), e003. https://doi.org/10.3989/estgeogr.201923.003

RESUMEN: El plano inédito de Sevilla de Manuel Spínola de Quintana (1827) es uno de los primeros documentos cartográficos que incluye la periferia de la ciudad amurallada. Por ello constituye una importante fuente para conocer dicho entorno extramuros, antes de su radical transformación a partir de mediados del siglo XIX. Después de revisar diversas fuentes documentales históricas y gráficas, e intervenciones urbanas de la época, el análisis se centra en el plano de 1827 y sus leyendas, que se compara con otros planos del propio Spínola (h. 1828-30) y Galiano Parra (1839). Finalmente se identifican los principales elementos estructurantes, como la muralla y puertas de la ciudad, caminos, red hidrográfica, puentes y alcantarillas, huertas y prados, así como hitos y elementos singulares tales como los arrabales y la arquitectura religiosa, agraria, militar, fabril, hospitalaria, funeraria, ventas, lavaderos, otros edificios públicos e intervenciones urbanas en espacios públicos, que por entonces conformaban el lugar estudiado y que aparecen representados en el plano.

PALABRAS CLAVE: periferia urbana; plano; Sevilla; siglo XIX; Manuel Spínola; extramuros.

\section{THE ENVIRONS OF SEVILLE IN AN UNPUBLISHED MAP BY MANUEL SPÍNOLA (1827)}

ABSTRACT: The unpublished map of Seville made by Manuel Spínola de Quintana (1827) is one of the first cartographic documents that includes the environs of the walled city. The map constitutes an important source of knowledge of the city's agrarian surroundings, which remained unchanged for centuries, until their radical transformation taken place since the middle of the 19th century. After reviewing historical and graphic documentary sources and urban developments happened at this time, the analysis focuses on the 1827 map, comparing it with other Spínola's map (1828-30) and one of Galiano Parra (1839). Finally, we have identified the main structuring elements of the studied area one by one, such as the urban fortification, roads, hydrographic network, bridges, orchards and meadows, as well as landmarks and other unique architectural evidences, such as suburbs and religious, hospitals, agrarian, military and industrial constructions, cemeteries, country inns, other public buildings as well as urban interventions in the public space, that are represented in the 1827 map.

KEY WORDS: environs; map; Seville; 19th century; Manuel Spínola; outskirts. 


\section{CONSIDERACIONES INICIALES}

El "Plano geométrico de los alrrededores [sic] de la M. N. M. L. M. H. ${ }^{1}$ Ciudad de Sevilla", de 1827, levantado por Manuel Spínola de Quintana se conserva hoy

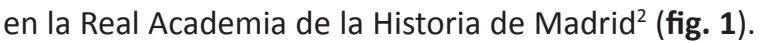
Es uno de los primeros planos de Sevilla que incluye el entorno exterior de la muralla histórica, un lugar que tuvo un carácter eminentemente agrario hasta las transformaciones acaecidas tras iniciarse el derribo de la muralla hacia mediados del siglo XIX. El análisis aquí abordado sobre dicho documento engloba intereses comunes de la geografía, la historia, el urbanismo y la arquitectura, que tratan de conocer y poner en valor elementos clave, en algunos casos desconocidos o perdidos, de la periferia urbana de Sevilla.

Así pues, el principal objetivo de este trabajo es profundizar, a través del plano inédito aportado, en el conocimiento de los espacios extramuros de SeviIla antes de su ocupación y transformación. Para ello se utiliza esta valiosa fuente documental gráfica que sintetiza la realidad física del momento, que ofrece datos no reflejados en otro tipo de documentos escritos, y que aporta una nueva visión de los principales elementos representados, tanto aquellos que estructuraban el espacio extramuros, como los hitos o arquitecturas singulares que componían el lugar estudiado a principios del siglo XIX.

Las ciudades medievales, tanto islámicas como cristianas, estaban protegidas por murallas -salvo excepciones muy contadas- que servían para defender sus habitantes de peligros externos, como medio de control a efectos fiscales y como símbolo del poder. En el caso de Sevilla -Spal, Hispalis, Isbiliya- situada en las fluctuantes orillas del Guadalquivir, su conjunto urbano evolucionó desde su primitiva implantación en un promontorio, definido por Collantes de Terán como "la Sevilla de la cota 14". La cerca perimetral y sus espacios extramuros se modificaron con el crecimiento urbano y los cambios del curso fluvial. En época almohade (1147-1248) los límites de la ciudad quedaron fijados con un imponente recinto amurallado, tras un largo proceso constructivo (Valor, 2002, p. 46). Dicho perímetro, con más de seis kilómetros, delimitó la ciudad hasta que se inició su demolición a mediados del XIX, momento en el que se aceleró la ocupación y expansión urbana extramuros con actividades que no tenían cabida en el casco histórico (Collantes de Terán, 1977, p. 95).

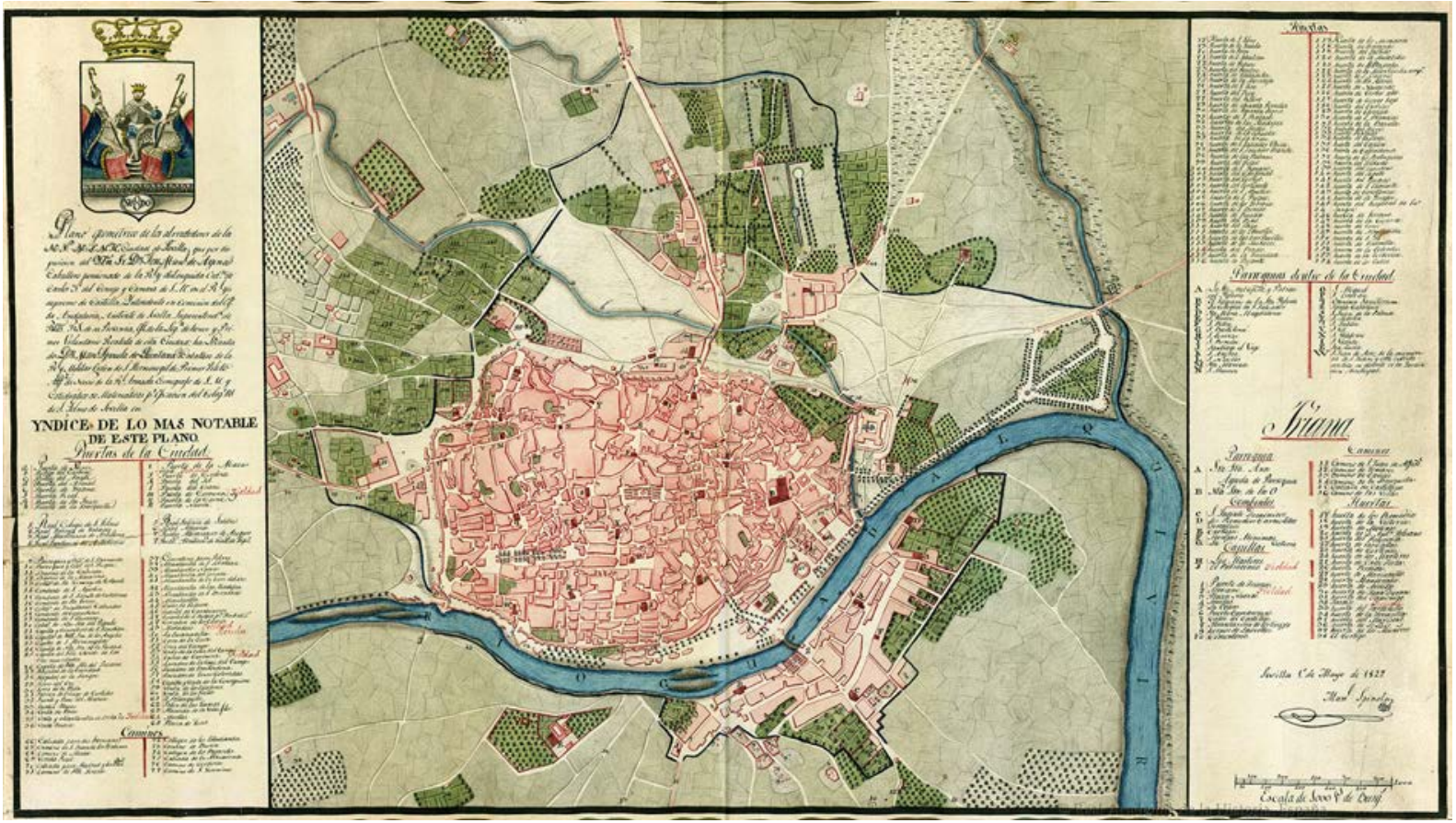

Fuente: ( Real Academia de la Historia, España. Autor Manuel Spínola de Quintana, 1827. Signatura C-Cuadros-11_Sevilla. 
El entorno externo e inmediato a la muralla estaba estructurado por una trama de caminos, calzadas y veredas; con sus correspondientes puentes y alcantarillas; por una compleja red hidrográfica (ríos, arroyos, lagunas y acueducto); junto con huertas, prados y dehesa; más arrabales. Además incluía diversos hitos arquitectónicos: religiosos (monasterios y conventos, iglesias y ermitas...), ligados a la agricultura (cortijos y haciendas, molinos de agua), militares (cuarteles), funerarios (cementerios), hospitalarios, fabriles, y otras edificaciones (plaza de toros, ventas, mercados, lavaderos...). Muchos de ellos estaban relacionados entre sí y profundamente vinculados con la ciudad.

Dichas relaciones entre el interior y exterior de la urbe se vieron alteradas a finales del siglo XVIII. Las murallas perdieron su valor defensivo debido a los cambios en la poliorcética, lo que propició su abandono y en algunos casos su demolición, en aras de un supuesto progreso, ya que llegaron a ser consideradas como un obstáculo físico y simbólico para el desarroIlo urbano (De Seta y Le Goff, 1991, p. 368). También influyeron factores económicos, como el alto coste de su mantenimiento y la incipiente especulación del valor del suelo extramuros; higiénicos, como la necesidad de abrir la ciudad para mejorar su habitabilidad; y sociales, como la demanda de aumentar el espacio urbanizable para hacerlo más asequible. A partir de este momento tuvo lugar una irreversible transformación de la periferia urbana en un espacio urbanizado, que aún hoy prosigue.

Desde la segunda mitad del siglo XVIII en Sevilla se plantearon intervenciones como el proyecto de sustitución de la coracha que unía la Torre del Oro y de la Plata por una arcada, firmado en 1809 por el arquitecto Manuel Cintoria, que retomó uno previo de $1784^{3}$. No obstante, el proceso de derribo del recinto amurallado se inició hacia 1820-18214 (Falcón, 1993, p. 223), según consta en el Archivo Municipal de Sevilla ${ }^{5}$, con la eliminación del lienzo que unía las torres del Oro y de la Plata. El asistente José Manuel de Arjona tomaría esta decisión por motivos relacionados con el tráfico y la mejora de la imagen de la ciudad, dando mayor continuidad a los paseos arbolados en la ribera del Guadalquivir.

Debe considerarse que las murallas continuaban ofreciendo una protección esencial, como defensa ante las cíclicas crecidas del río que inundaban la ciudad. Por eso durante el mandato de Arjona (18251833) se efectuaron trabajos de conservación y consolidación, con cargo al Ayuntamiento y a la Real Hacienda, para evitar su ruina y como prevención ante futuras riadas (Carriazo, 1951, p. 31-32). Además, por entonces se mantenía intacto el valor de la muralla como límite jurídico-fiscal, y para recaudar el "derecho de puertas" o impuesto sobre las mercancías que llegaban a la ciudad.

Los derribos se retomaron con motivo de las obras del ferrocarril Sevilla-Córdoba (h. 1858) que crearon una nueva barrera frente al río por el flanco oeste de la ciudad y hacía innecesaria la cerca en ese frente urbano. Tras la Revolución Gloriosa de 1868 prosiguió el proceso de demolición, que condujo a la práctica desaparición de casi toda la muralla de Sevilla. Únicamente se salvaron parte del tramo norte entre la puerta de la Macarena y la de Córdoba, también del sur por la presencia de los Reales Alcázares, y algunos vestigios sobre los que se adosaron edificaciones. De este modo se diluyeron los tradicionales límites urbanos y se aceleró la ocupación de la periferia ya iniciada siglos atrás.

En contraste con los abundantes estudios que existen sobre el casco histórico de Sevilla, pocos han analizado su entorno extramuros. Entre los trabajos pioneros debe citarse "Sevilla extramuros. La Huella de la Historia en el Sector Oriental de la Ciudad" coordinado por Valor Piechotta y Romero Moragas (1998), y la publicación de Díaz Garrido (2010) que estudia el barrio de Triana en el sector occidental. También cabe destacar las recientes aportaciones de Gámiz Gordo y Díaz Zamudio sobre Sevilla extramuros en el siglo XVI (2019) y de Díaz Zamudio y Gámiz Gordo (2018) centrado en las vistas de la periferia urbana sevillana hasta finales del siglo XVIII. Sobre el contexto histórico de la Sevilla del XIX, la obra de Cuenca Toribio (1976) analiza su realidad económica, política, social y cultural; De la Banda y Vargas (1972) aborda la historia del urbanismo sevillano en dicho siglo; y Suárez Garmendia (1986) la arquitectura y el urbanismo del XIX. Asimismo resulta de interés el estudio de Braojos Garrido (1976) sobre el asistente Arjona entre 1825-1833, un periodo que coincide con la elaboración del plano aquí estudiado.

Por otra parte debe indicarse que el plano de Spínola de 1827 fue levantado antes de la Real Orden de 25 de julio de 1846, que obligaba a los ayuntamientos a ejecutar un plano geométrico de sus núcleos urbanos. Además, cabe destacar otras cartografías de ciudades españolas que incluyen su periferia urbana, como el plano de Málaga y sus contornos de Bartolomé Thurus de 1717, el mapa topográfico de la ciudad de Granada y su término de Francisco Dalmau de 1819, y otros muchos cuyo análisis rebasa el alcance de este artículo (Urteaga y Nadal, 2017). 
En cuanto a fuentes documentales gráficas resulta indispensable la consulta de la publicación "Planos de Sevilla. Colección histórica (1771-1918)" de Cortés José, García Jaén y Zoido Naranjo (1992), que incorpora un breve estudio sobre el llamado plano del Infante Don Carlos, de Manuel Spínola de Quintana (h. 18281830) (fig. 2), pero no incluye el plano de Spínola (1827) aquí analizado, ni otro relacionado con éste, el de Manuel Galiano Parra (1839) (fig. 3).

Como punto de partida seguidamente se revisan estos documentos gráficos coetáneos y se contextualiza el plano de Manuel de Spínola de 1827, comparado con ellos; para después acometer el análisis de la periferia de Sevilla representada, sus elementos estructurantes y principales hitos.

\section{Planos coetáneos de SeVilla y su periferia uRbana}

Como antecedentes del documento de Spínola, cabe mencionar los dos planos urbanos de finales del siglo XVIII, el de Olavide (1771) y el de López de Lerena (1788).
El primero fue un encargo del asistente Pablo de Olavide, levantado por Francisco Manuel Coelho, y grabado por Joseph Amat. Se le suele considerar como el primer plano de la ciudad, pero sólo incluye un entorno muy próximo al recinto amurallado, sin representar los arrabales de San Bernardo y la Calzada (Algarín, 2000; Cortés et al., 1992, p. 2224). El segundo, dedicado al asistente Pedro López de Lerena, fue levantado por Tomás López de Vargas y Machuca, copiando el de Olavide, como el propio autor indica, con ciertas actualizaciones y cambios, e incluyendo el arrabal de Triana con mayor definición (Cortés et al., 1992, p. 25-26).

Durante la invasión de la ciudad por el ejército napoleónico (1810-1812) se elaboró una minuciosa cartografía por parte de los ingenieros-geógrafos militares del Bureau Topographique de l'Armée d'Espagne, depositada en el Dépôt de la Guerre y hoy conservada en el Service Historique de la Défense en París (Castañón y Puyo, 2008; Centro de Documentación de Defensa, 2008, p. 20). Estos planos tienen un carácter esencialmente

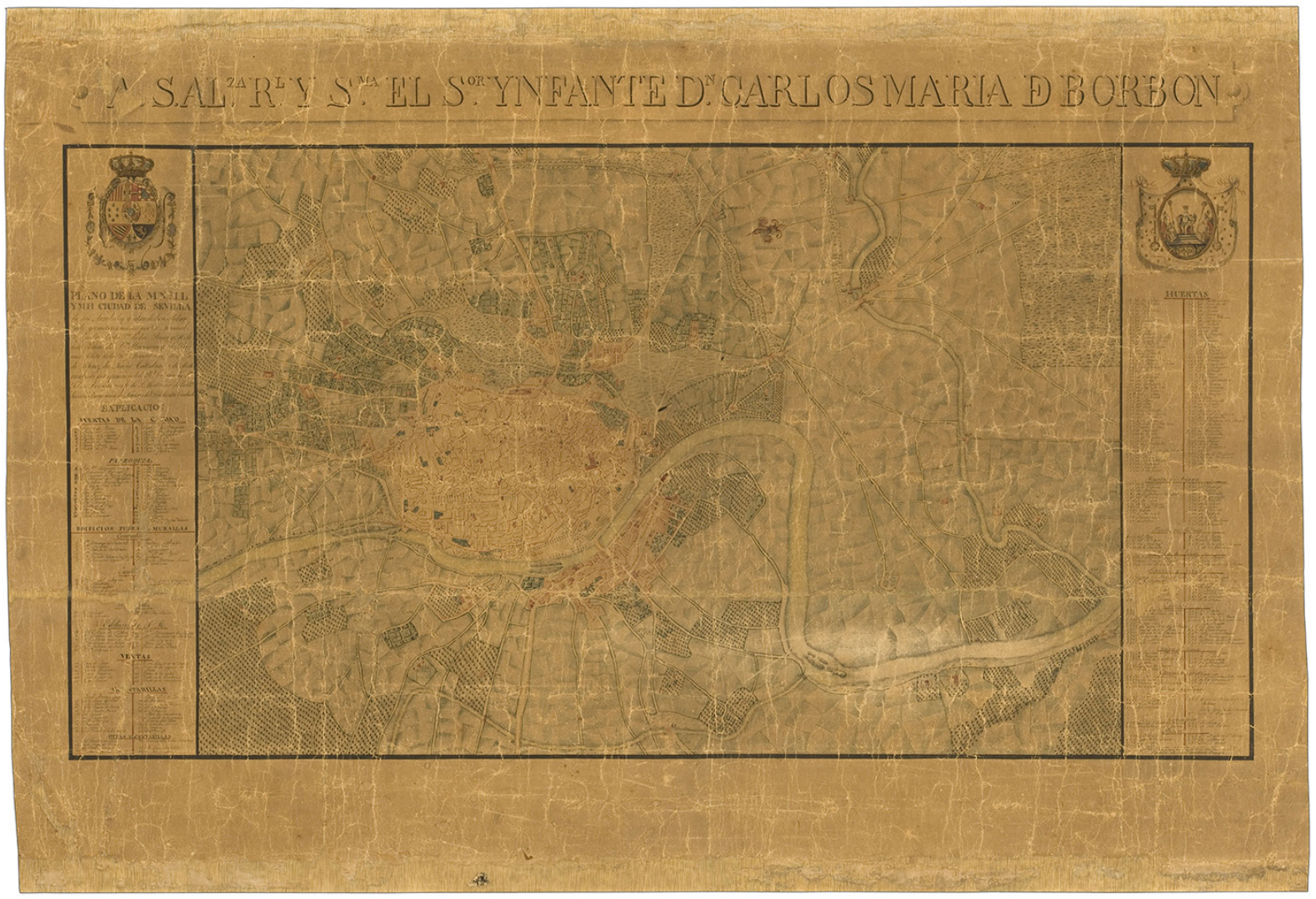

Fuente: @ ICAS-SAHP, Archivo Municipal de Sevilla, España. Autor Manuel Spínola de Quintana, h. 1828-1830. Signatura II-5-2. 


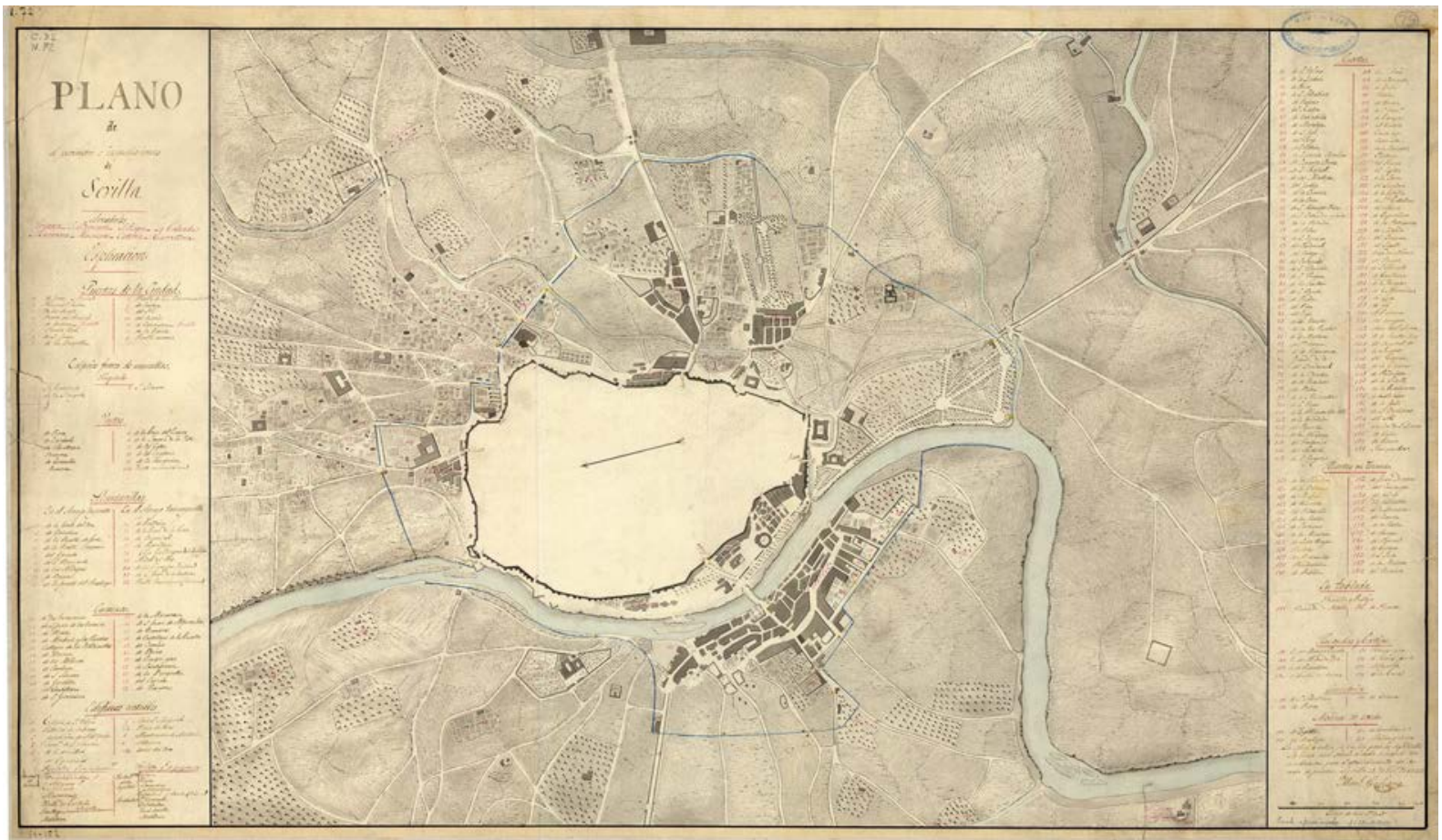

Fuente: (C Instituto Geográfico Nacional, España. Autor Manuel Galiano Parra, 1839. Signatura 31-E-3.

territorial, incluyendo no sólo el entorno de Sevilla, sino también las poblaciones de la cornisa del Aljarafe, los Alcores, la campiña de Carmona y la Vega del Guadalquivir, razón por la que no se incluyen en este estudio.

El siguiente plano fue el de Manuel Spínola de Quintana (1827), objeto de este artículo, que poco después ejecutó otro, Ilamado del Infante Don Carlos (aquí datado hacia 1828-1830). Más tarde se realizó el de José Herrera Dávila (1832); el de Ildefonso Sierra (1837); y el de Manuel Galiano Parra (1839). Entre ellos se ha prestado especial atención al del Infante Don Carlos y al de Manuel Galiano, como referencias imprescindibles para analizar el de Spínola.

El mencionado "Plano Topográfico de la Ciudad de Sevilla, y de sus inmediaciones hasta una distancia de 1200 varas de radio" de José Herrera Dávila, se incluyó en su Guía de Forasteros (Herrera, 1832) autorizada por el asistente Arjona en $1828^{6}$. Es bastante conocido y su original se encuentra en el Archivo Municipal de Sevilla. Es muy similar a los de Olavide y de López de Lerena, pero incluye un detalle a distinta escala con los alrededores de la urbe (Cortés et al., 1992, p. 2728). Su leyenda incorpora abundantes referencias que ponen en valor dicho entorno.
El plano militar de Ildefonso Sierra de 1837 se encuentra en el Archivo General Militar de Madrid (Instituto de Historia y Cultura Militar). Incorpora las obras ejecutadas en 1836 por el ejército para una mejor defensa de la ciudad, incluyendo barrios y caseríos adyacentes, pero sin representar la ciudad intramuros. Fue publicado por González Cordón (1985, p. 18), sin un análisis del mismo, y también fue descrito en un artículo de Suárez Garmendia (1999).

El citado corpus gráfico refleja el interés creciente que existió por representar la periferia urbana hispalense, detallada en el plano de Spínola aquí analizado.

\section{El PLANO de SPínOla (1827). CONTEXTO, DESCRIP- CIÓN Y ANÁLISIS COMPARADO}

\subsection{Intervenciones urbanas en Sevilla en tiempos del asistente Arjona}

El plano de Spínola fue redactado durante el gobierno del asistente Arjona en Sevilla (1825-1833). Refleja destacadas intervenciones urbanas que incorporaron jardines y paseos arbolados, antes de las grandes transformaciones extramuros como la llegada del ferrocarril, el inicio de la reforma del Guadalquivir y del 
puerto, la implantación de fábricas de capital privado y los nuevos crecimientos urbanos.

Para comprender mejor el contexto de la época, debe considerarse la singular figura de José Manuel de Arjona y Cubas (1781-1850) artífice de importantes actuaciones urbanas tras años de inoperancia ${ }^{7}$. Junto a él destacó la labor del Arquitecto Mayor de la ciudad, Melchor Cano (1794-1842) desde 1826 (Antigüedad, 1990, p. 417), que acaparó diversos cargos en instituciones civiles y religiosas, e intervino en obras públicas tanto intramuros como extramuros.

Por entonces se aprobó una nueva normativa sobre actuaciones urbanísticas, el Reglamento de Policía Urbana (1828) "para el mejor ornato y aspecto público, seguridad, salubridad, aseo y limpieza de las calles" (Antigüedad, 1990, p. 435-336; Braojos, 1976, p. 306307). Además se acometieron diversas obras, como la pavimentación de calles (Marín y del Pozo, 1986, p. 65-67); la modernización del alumbrado público; la normalización del suministro y abastecimiento de agua; la regularización y mejora del viario y salubridad en calles; la eliminación de soportales... Éstas se inspiraron sin duda en preceptos urbanísticos ilustrados propios del siglo XVIII.

Las operaciones en la periferia de la ciudad adquirieron cierta notoriedad, como paso previo a la expansión de Sevilla hacia el sur. Se generalizó el uso de vegetación para ordenar paseos arbolados o ajardinados, recuperándose sectores desordenados o insalubres, como muladares y basureros. Estos espacios verdes funcionarían como una nueva transición entre la ciudad y el campo. De este modo se conformaron espacios para el recreo y la socialización, incorporando la naturaleza domesticada en la ciudad.

Debe considerarse que intramuros también había zonas ajardinadas privadas: huertas, patios de casas o palacios, y claustros; pero las de tipo público eran escasas. Uno de los espacios más destacados era la Alameda de Hércules: en el siglo XVI el Conde de Barajas había desecado y adecentado la Laguna de la Feria, sobre el antiguo cauce del Guadalquivir, que fue objeto de otros arreglos bajo el mandato de Arjona. También cabe recordar la creación de plazas tras la ocupación napoleónica (18101812), con el derribo de conventos (Agustinas Recoletas de la Encarnación, parcialmente San Francisco) e iglesias (Santa Cruz, Magdalena) que trataron de descongestionar el saturado tejido urbano intramuros.

Las actuaciones extramuros del asistente Arjona tuvieron precedentes en el siglo XVIII, en los paseos ajardinados ribereños de los asistentes Pablo de Olavide,
Pedro López de Lerena y José Ávalos o Dávalos. En los inicios del XIX cabe destacar dos intervenciones emblemáticas de Arjona que transformaron el frente del río. Ambas fueron diseñadas por Melchor Cano y su plantación fue tutelada por el célebre profesor de agricultura y botánica Claudio Boutelou. Estaban organizadas con un salón central elevado, árboles laterales, bancos de piedra con respaldos de hierro, fuentes, estanques, floreros y esculturas decorativas (Herrera, 1832, p. 3841). Una de ellas fue el Paseo de Las Delicias, conocido como Las Delicias de Arjona (1826-1829), situado junto al ampliado paseo de Bella Flor o "alameda de la Vellaflor [sic]" (según la leyenda del plano), al Guadalquivir y al arroyo Tamarguillo, en una parcela triangular en desuso arrendada al industrial inglés Wetherell. En él se plantaron muchas especies vegetales, algunas exóticas provenientes de Cuba, a modo de jardín botánico, que sirvió como vivero. Para su riego se extraía agua del río con una máquina de vapor, situada en un pabellón de estilo neogótico. La otra intervención emblemática fue el Salón de Cristina (1828-1830), situado entre la fachada principal del Palacio de San Telmo, la puerta de Jerez, el tramo final del arroyo Tagarete y la orilla del Guadalquivir, que antes fue un vertedero. También disponía de una máquina de vapor para el riego, y un llamativo pabellón chinesco. Este lugar se puso de moda como punto de encuentro para la sociedad sevillana (Ford, 2008, p. 222).

Otras operaciones extramuros fueron la implantación de varios cementerios, promovidos tras la Real Cédula de 3 de abril de 1787 que proponía su ubicación lejos de la ciudad. Durante el mandato de Arjona se acordó la construcción de dos camposantos extramuros, uno en cada margen del río: el de San Sebastián (1827) del anterior Arquitecto Mayor, Julián de la Vega, junto a la ermita del mismo nombre (Rodríguez, 1996, p. 68-70; Suárez, 1986, p. 56-59); y el de Triana al oeste del arrabal, sustituido posteriormente por el de San José (1833), de Melchor Cano, junto al monasterio de la Cartuja (Rodríguez, 1996, p. 77-79; Suárez, 1986, p. 59-61). Éstos se sumaron a los ya existentes de San Lázaro, contiguo al hospital del mismo nombre, al norte de la ciudad, y al conocido como cementerio de los pobres en la zona de Eritaña, al sur.

En estas fechas se construyó el nuevo mercado de abastos de Triana (1823) sobre el lugar que ocupaba el castillo de San Jorge, proyecto y obra de Tomás de Escacena y Anaya. Y también cabe destacar la nueva plaza de Armas, antes llamada Campo de Marte, inaugurada el 30 de Mayo de 1833 como espacio destinado a ejercicios militares que ocupó un terreno yermo 
junto al almacén de Maderas del Rey, entre la puerta de Triana y la puerta Real.

\subsection{El plano de Manuel Spínola de 1827}

Incluye el título "Plano geométrico de los alrrededores [sic] de la M. N. M. L. M. H. Ciudad de Sevilla" (fig.1) y está fechado en dicha ciudad el 1 de Mayo de 1827 por encargo del asistente Arjona, según la leyenda, que contiene la firma del autor. Hoy se conserva en la Real Academia de la Historia, tras adquirirse en una reciente subasta ${ }^{8}$, junto a otros seis planos de poblaciones de la provincia de Sevilla, también levantados por Spínola bajo la iniciativa del mismo Asistente.

Manuel Spínola de Quintana (1770-1833), o Manuel Espínola Quintana ${ }^{9}$, nació en Moguer (Huelva), y tras su paso por la Universidad de Mareantes de Sevilla, llegó a ser primer piloto honorario y alférez de fragata de la Real Armada ${ }^{10}$, cosmógrafo, cartógrafo y catedrático de Matemáticas por oposición en el Real Colegio Seminario de San Telmo (Manso, 2013, p. 302303). Fue socio facultativo en Matemáticas de la Real Sociedad Económica de Amigos del País de Sevilla ${ }^{11}$. Destacó por la realización de un atlas de la costa occidental de la América meridional (Martínez y Alfonso, 2009, p. 341). Al final de su carrera prestó sus servicios al asistente Arjona, que también era intendente en Comisión del Ejército de Andalucía, y superintendente de Rentas Reales de la provincia de Sevilla. Por ello Arjona le encargó planos de poblaciones de la actual provincia de Sevilla, para el adecuado control y el restablecimiento de las Rentas Reales en poblaciones de más de 15.000 habitantes, según Real Decreto de 16 de febrero de $1824^{12}$. Así, Spínola elaboró planos de Utrera (1825), Carmona (1825), Marchena (1826), Morón (1826), Osuna (1826), Écija (1826) y Sevilla (1827), cabeceras de partidos de la provincia ${ }^{13}$.

El plano de Sevilla, manuscrito con tinta negra y aguada a color sobre papel, mide $51 \times 75 \mathrm{~cm}^{14}$ y tiene una escala gráfica de 1000 varas de Burgos $^{15}$, según leyenda. Se orientó con el norte hacia la izquierda, al igual que el plano de Olavide y otros posteriores, aunque éste no se dibujó. Las edificaciones tienen color rosado, más oscuro en las más significativas.

Cabe destacar una línea azul no indicada en la leyenda, que parece marcar el perímetro del recinto para los Derechos de Puertas o impuestos de mercancías (Braojos, 1976, p. 182-84). Además en leyenda se señalan los fielatos (junto a ellos se escribe en rojo "fieldad") que se situaban en la puerta de la Macarena, puerta de Carmona, Matadero, venta de
Eritaña, Caños de Carmona y en Triana en el Altozano, en la huerta llamada Jardín y junto a la capilla de El Patrocinio.

La leyenda se sitúa en ambos laterales e incluye el título "Yndíce [sic] de lo mas [sic] notable de este plano" (fig. 4). En la parte superior de la franja izquierda aparece el escudo de la ciudad. Más abajo se incluye el citado título, una dedicatoria al asistente Arjona, un resumen de su curriculum y cargos; más el nombre del autor del plano y algunas de sus distinciones. También se ofrece un listado de las puertas de la ciudad, instituciones de fundación real, barrios, conventos, capillas, hospitales, fábricas, torres, jardines, ventas, cementerios, alcantarillas, casas, cuarteles, matadero, lavaderos, plazas, caminos, veredas y calzadas. Las puertas de la ciudad se designan con letras minúsculas de la "a" a la "ñ" y el resto de elementos con los números del 1 al 77.

FIGURA 4

DETALLE DE LAS LEYENDAS IZQUIERDA Y DERECHA DEL PLANO GEOMÉTRICO DE LOS ALRREDEDORES [SIC] DE LA M. N. M. L. M. H. CIUDAD DE SEVILLA
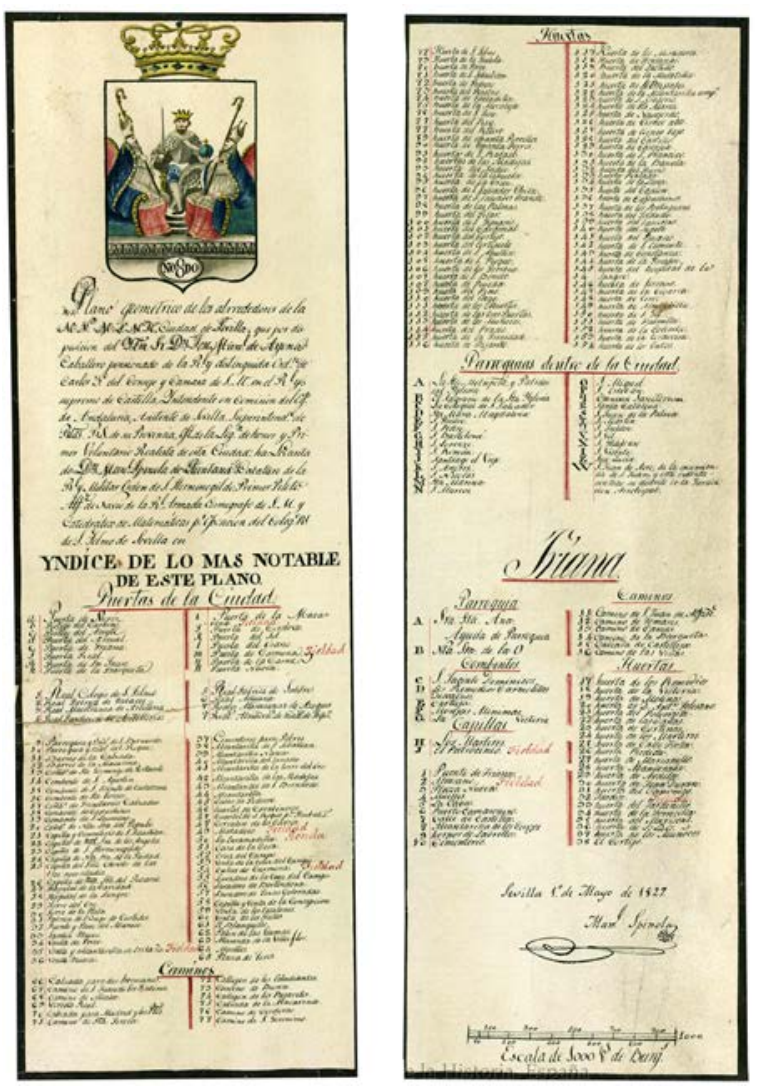

Fuente: (C) Real Academia de la Historia, España. Autor Manuel Spínola de Quintana, 1827. Signatura C-Cuadros-11_Sevilla. 
En la franja derecha, la leyenda indica huertas y parroquias del sector oriental de la ciudad, y elementos de Triana: parroquias, conventos, capillas, construcciones singulares, caminos y calzadas, y las huertas; numerados del 78 al 154 (huertas orientales) y con letras mayúsculas de la " $A$ " a la "W" (parroquias intramuros). En el resto de elementos del sector occidental se repiten las letras mayúsculas, de la "A" a la "J" y números del 1 al 38.

Los citados planos de otras poblaciones de Sevilla tienen un cuidadoso diseño, similares criterios de representación y alrededores detallados, pero con diversas escalas. También están manuscritos con tinta negra y aguada a color, aunque su orientación es diferente y el norte se representa con símbolos distintos. Todos incluyen una amplia leyenda explicativa con el escudo de la ciudad, dedicatoria al promotor de los mismos, firma del autor y los elementos más notorios referenciados con letras o números (Fajardo, 2016, p. 42).

En todos ellos, salvo en Utrera, se representa una alameda para el recreo. Dichos espacios se idearon como paseo y jardín, con hileras de árboles, bancos, fuentes y esculturas, y solían situarse en los accesos a la ciudad (Quirós, 2009, p. 196-197). Este tipo de intervenciones "de embellecimiento urbano", que vendrían de la mano del asistente Arjona, tuvieron antecedentes en su etapa en Madrid como corregidor (1816-1820), en el paseo de las Delicias de dicha ciudad; que inspiraría los ya citados paseo de las Delicias y el Salón de Cristina en Sevilla.

Resulta evidente el interés por marcar los límites de la ciudad a nivel fiscal, para recaudar impuestos sobre mercancías destinados a las Rentas Reales, indicados con una línea azul oscuro, o negra en el caso de Utrera. Además se indican "las obras que se han de hacer para el cerramiento de la Población", con una línea amarilla, que en Utrera y Carmona señala el antiguo perímetro de la muralla.

Otra cuestión a considerar en el plano aquí estudiado es su fiabilidad métrica ${ }^{16}$. Puede afirmarse que los distintos elementos urbanos extramuros están bien situados, aunque existen ciertas diferencias dimensionales, y a veces se esquematizan o se simplifican muchos elementos representados.

\subsection{Análisis comparado entre los planos de $1828-30$ y 1839}

Para profundizar en el análisis del plano de Spínola seguidamente se identifican las principales diferencias con planos ya citados, fechados hacia $1828-30$ y en 1839 , con los que compartiría base geométrica, según se indica más adelante.

El "Plano de la M. N. M. L. y M. H. ciudad de SeviIla, de sus Arrabales y alrededores", dedicado "A. S. $A^{\text {za }}{ }^{\text {. }} \mathrm{R}^{\prime}$. Y S $\mathrm{S}^{\mathrm{ma}}$. El $\mathrm{S}^{\text {or }}$. Ynfante $\mathrm{D}^{\mathrm{n}}$. Carlos María de Borbón"17, más conocido como el plano del Infante Don Carlos (Cortes et al., 1992, p. 8) (fig. 2) fue levantado por Manuel Spínola de Quintana hacia 1828-1830. Se conserva en el Archivo Municipal de Sevilla, mide $55 \mathrm{x}$ $95 \mathrm{~cm}$ y su estado de conservación es delicado, a pesar de su reciente restauración ${ }^{18}$. Está manuscrito con aguada a color sobre papel entelado, con escala de 1000 Varas de Burgos, indicada en el propio plano. En la leyenda se indican las puertas de la ciudad, parroquias, conventos, capillas, hospitales, edificios de Su Majestad, ventas, alcantarillas, huertas, lavaderos de lana, haciendas y cortijos, caminos, molinos de agua, cementerios, y paseos.

El "Plano de el [sic] perímetro e inmediaciones de Sevilla, Arrabales: Triana, San Bernardo, San Roque, La Calzada, Macarena, Humeros, Cestería, Carretería" (fig. 3), se conserva en el Instituto Geográfico Nacional, fue dibujado por el arquitecto Manuel Galiano Parra y está fechado el 31 de Enero de $1839^{19}$. Se ejecutó con aguada a color sobre papel montado en tela, mide $50,5 \times 89,5 \mathrm{~cm}$, sobre hoja de $53,5 \times 91,5 \mathrm{~cm}$, e incluye escala de 1000 varas castellanas. En la leyenda se referencian las puertas de la ciudad, hospitales, ventas, alcantarillas, caminos, edificios notables, fielatos, huertas, haciendas y cortijos, y molinos de agua.

Al superponer dichos planos con el de 1827 se comprueba que se aproximan bastante y tienen contenidos similares, pareciendo los últimos una versión actualizada. No obstante, éstos dos abarcan un territorio algo más amplio, lo que hace pensar en una toma de datos común (fig. 5). El plano de 1839 se obtuvo a partir de los de Spínola, incluyendo ciertas transformaciones como las relacionadas con la Desamortización de Mendizábal de $1836-37^{20}$.

Respecto a criterios de representación, algunos elementos se esquematizan en todos ellos. En el de 1828-30 no se aprecia el perímetro del "derecho de puertas", incluido en los otros. Y en los planos de Spínola se representa el casco histórico, pero en el de Galiano aparece en blanco.

El de 1828-30 parece ser un plano dedicado a dicho Infante, pues en su leyenda se indican las propiedades de Su Majestad. En cambio, el plano de 1839 respondería a fines aduaneros o tributarios, pues aparece la citada línea azul y en su título dice plano del 

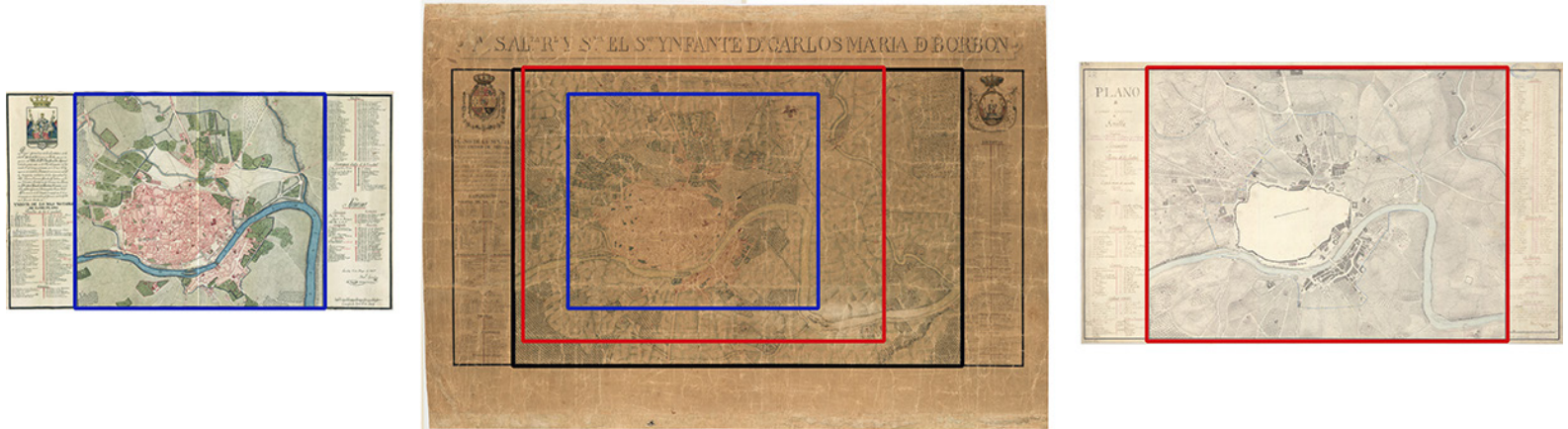

Fuente: (C) Real Academia de la Historia, España. Manuel Spínola, 1827. Signatura C-Cuadros-11_Sevilla. C Instituto Geográfico Nacional, España. Autor Manuel Galiano Parra, 1839. Signatura 31-E-3. C ICAS-SAHP, Archivo Municipal de Sevilla, España. Manuel Spínola, h. 1828-1830. Signatura II-5-2. Leyenda: Contorno del plano de 1827 (línea azul), Contorno del plano de h.1828-1830 (línea negra), Contorno del plano de 1839 (línea roja).

“...perímetro..." que correspondería con los límites fiscales. Además se resaltan los fielatos y casillas de fieldad en los que se cobraban los Derechos de Puertas.

Existen diferencias en los cementerios y jardines representados. El cementerio para pobres se sitúa en los tres planos ( $n$ - 37, 274 y 196) al sur de la ciudad, junto al arroyo Tamarguillo y cerca de la venta Eritaña. En cambio el cementerio de San Sebastián ${ }^{21}$ se representa con geometrías distintas (no 21, 273 y 195), aunque no su ermita. Junto a ella, el nuevo camposanto se añadió a los preexistentes privados. Respecto al cementerio de Triana, trasladado a la huerta de la Torrecilla junto al camino de Tomares, solo aparece en los dos primeros planos ( $n-10,275)$ porque se trasladó nuevamente en 1833 a las inmediaciones de monasterio de la Cartuja (no 197).

También difieren el paseo de La Delicias y el Salón de Cristina en los tres planos. El primero se designa como Jardín Nuevo en el plano de 1827 (no 33). Las obras estarían más avanzadas en el de 1828-30 ( $n$ 으 283), que ya indica su nuevo nombre. Todos ellos reflejan similar geometría, pero leves diferencias en detalles. El Salón de Cristina sólo aparece referenciado en la leyenda del plano del Infante Don Carlos (no 281), pues se empezó a materializar a partir de 1828 y por ello el plano de 1827 refleja el estado previo. Llama la atención que en la leyenda del plano de 1839 no se incluyeron estas dos emblemáticas operaciones de Arjona.

\subsection{Nueva datación del plano del Infante Don Carlos}

Se desconoce la fecha exacta de ejecución del plano del Infante Don Carlos. Collantes de Terán (1970, p. 28) lo dató hacia 1830 y otros autores suelen aceptar el año 1827, siguiendo la hipótesis de Braojos (1976, p. $308)$, que relaciona este plano con un oficio de $1827^{22}$, en el que Manuel Spínola ofrecía al Cabildo municipal un plano de los alrededores de Sevilla. Los límites físicos del plano de 1828-30 concuerdan con los descritos en dicho oficio ${ }^{23}$, ambos documentos depositados en el Archivo Municipal de Sevilla.

Sin embargo estos datos no son concluyentes, pues en la época era habitual hacer copias de un mismo plano, y depositarlas en distintas instituciones con cartelas y decoraciones o dedicatorias específicas (Manso, 2012a, p. 15). De hecho, se ha localizado un documento inédito en los archivos de la Real Sociedad Económica de Amigos del País de Sevilla ${ }^{24}$ que relata la entrega de una copia a dicha Institución ${ }^{25}$

El citado oficio municipal dice que el plano se dedica al asistente Arjona y no al Infante Don Carlos María de Borbón. Hubiese resultado extraño que se dedicase a éste, si se consideran las tensiones de esas fechas por la sucesión al trono ${ }^{26}$. Es difícil imaginar que el asistente Arjona apoyase tal dedicatoria, pues siempre demostró fidelidad a Fernando VII, con la esperanza de regresar de nuevo a la corte en Madrid (Braojos, 1976, p. 495-497).

Es posible que el plano de Sevilla entregado el 27 de mayo de 1827 (aludido en el oficio citado) sea el aquí estudiado, fechado el 1 del mismo mes, cuya existencia desconocía Braojos Garrido. Ante la falta de datos concluyentes, el propio Archivo Municipal de Sevilla fechó su plano hacia 1827-1830. 
Al comparar el Salón de Cristina (1828-1830) en ambos planos (fig. 6) resulta evidente que el de 1828-1830 es posterior. El nombre de este espacio "De Apolo en Sn. Telmo" según su leyenda, aludiría a una estatua de Apolo de Belvedere en la fuente del paseo principal, que no llegó a ejecutarse (Braojos, 1976, p. 331). El plano del proyecto de Melchor Cano, entregado en el Ayuntamiento el 9 de agosto de 1828, refleja esta denominación (fig. 6). El Salón se inauguró el 24 de julio de 1830, en la onomástica de la segunda esposa de Fernando VII que le dio nombre (Braojos, 1976, p. 332-333).

Por todo ello, puede datarse el plano del Infante Don Carlos entre 1828 y 1830, fechas de inicio y finalización de las obras del Salón de Cristina, considerando también la Pragmática Sanción que apartaba del trono al Infante, aprobada en 1830.

\section{SeVilla extramuros en el PLANO de SPínOla}

Para analizar de forma ordenada los espacios de la periferia urbana de Sevilla resulta útil considerar diferentes categorías en sus elementos estructurantes y elementos singulares o hitos. Los elementos estructurantes serían aquellos que articulan y jerarquizan el territorio, como parte de una red o conjunto que no debe considerarse de forma aislada (fig. 7). Por otra parte, los elementos singulares o hitos suelen ser arquitecturas que se convierten en puntos de interés urbano (fig. 8). Todos ellos aparecen representados, e identificados en su mayoría, en el plano de Spínola de 1827.

\subsection{Elementos estructurantes}

\subsubsection{Muralla y puertas de la ciudad}

Según el plano de Spínola el recinto amurallado tenía quince puertas o postigos y más de un centenar de torres ${ }^{27}$. Las puertas eran las siguientes: de Xerez [sic]; del Arenal; de Triana; Real (o de Goles); de San Juan; de la Barqueta (o de la Almenilla o Vib-Arrangel); de la Macarena; de Córdova [sic]; del Sol; del Osario; de Carmona; de la Carne; y Nueva (o de San Fernando); más los postigos del Carbón y del Aceyte $\left[\right.$ sic] ${ }^{28}$. De ellas hoy solo se conservan la puerta de la Macarena, el postigo del Aceite y la puerta de Córdoba como capilla aledaña a la iglesia de San Hermenegildo.

En cuanto a las murallas, son pocos los tramos que se conservan emergentes y exentos, como los existentes entre las puertas de la Macarena y de Córdoba o, entre las puertas de la Carne y el postigo del Alcázar, llamado Muro del Agua. La antigua área residencial del Real Alcázar también conserva parte importante de sus murallas y puertas. Además, hoy gran parte de la cerca urbana se conserva soterrada o embutida en el caserío. Sin embargo, el cuadrante noroeste fue demolido hasta la rasante del terreno con motivo de la construcción del ferrocarril y la implantación de nuevas industrias.

\subsubsection{Caminos}

En el sector oriental se reflejan, según leyenda, las calzadas para: Dos Hermanas, Madrid y los Puertos (Cádiz), San Juan de los Teatinos y la Macarena; también los caminos de: Alcalá, Sta. Teresa, Buron, Cordova [sic], S. Geronimo [sic] y los callejones de los
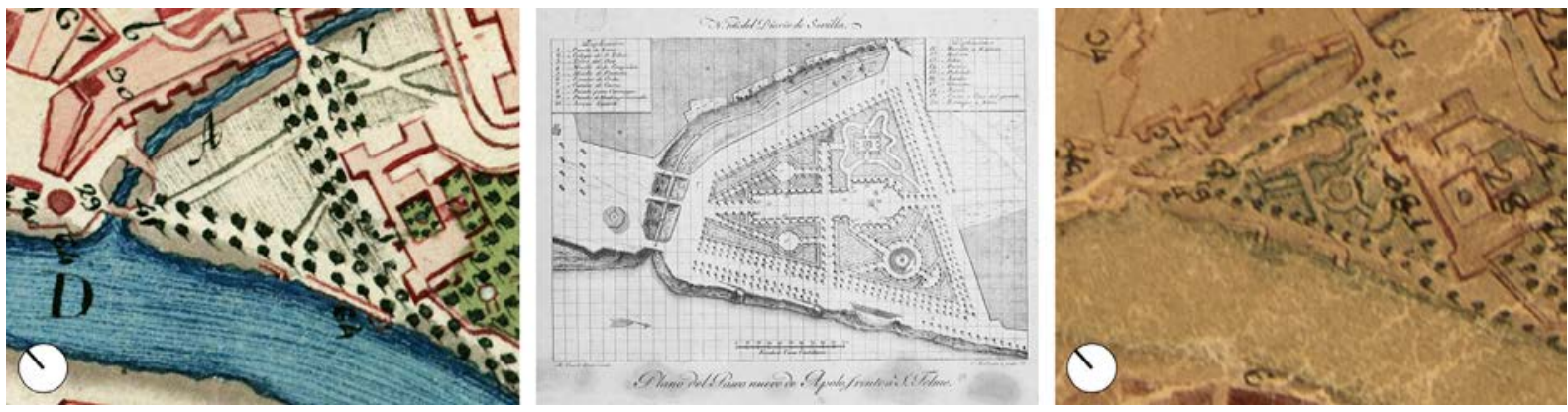

Fuente: (C) Real Academia de la Historia, España. Manuel Spínola, 1827. Signatura C-Cuadros-11_Sevilla. @ Biblioteca Nacional España. Plano del Paseo nuevo de Apolo. Melchor Cano, h.1828. Signatura MV/14. C ICAS-SAHP, Archivo Municipal de Sevilla, España. Manuel Spínola, h. 1828-1830. Signatura II-5-2. 
Estudiantes y de los Pajaritos. Otros solo citados en el plano del Infante Don Carlos son los del Copero, de los Molinos, de San Lázaro, de la Corza, de la hacienda de San Jacinto, de la Vereda Real y el callejón del Almez.

En Triana, cabe destacar los caminos hacia San Juan de Aznalfarache, Tomares, Camas, Castilleja y otros de menor rango como los de la Barqueta y de las Viñas. Algunos fueron dibujados y solo citados en el plano del Infante Don Carlos: los de Campogaz, de San Luis, y del Alamillo. Muchos han sobrevivido como calles, con ligeras rectificaciones, y en otros casos se ha mantenido su topónimo.

\subsubsection{Red hidrográfica}

Junto al elemento principal, el río Guadalquivir, tenía cierta importancia el río Guadaira, fuera del ámbito dibujado. También se representan los arroyos Tagarete y Tamarguillo en el sector oriental. Su nombre aparece escrito sobre cada uno, pero no en leyenda. Todos funcionaron como barreras naturales, delimitando espacios extramuros. A lo largo del siglo XX fueron encauzados, cubiertos o modificados en su recorrido, para favorecer la continuidad urbana y prevenir inundaciones.

El conocido acueducto de los Caños de Carmona, principal suministro de agua de la ciudad y de algunas de sus huertas, aparece representado en su parte aérea desde el entorno de la Cruz del Campo. Provenía de las inmediaciones de Alcalá de Guadaira, y entroncaba con la muralla en la puerta de Carmona. Este elemento transformó el paisaje en su recorrido, con molinos hidráulicos y sistemas de irrigación, especialmente desde Torreblanca, donde el agua era transportada a través de un canal, hasta la Cruz del Campo, donde se inicia la estructura aérea hasta Sevilla, con poco más de 1,5 $\mathrm{km}$. Hoy se conservan algunos tramos en la calle Luis Montoto, antes denominada de Oriente. Además en el plano aparece la importante Fuente del Arzobispo, hoy conservada en los huertos de Miraflores, con agua de excelente calidad que complementaba a dicha estructura, abasteciendo fuentes públicas intramuros, especialmente del entorno de la Alameda de Hércules.

\subsubsection{Puentes y alcantarillas}

El puente más conocido era el de barcas sobre el Guadalquivir, en la ubicación del actual Puente de Isabel II, que conectaba la ciudad con Triana, las poblaciones del Aljarafe y la zona occidental de Andalucía y Extremadura. Su construcción data del año 1171, bajo el califato almohade; después de la conquista cristiana la propiedad fue del concejo sevillano que lo arrendaba a particulares.
El resto de puentes referenciados en la leyenda, con menor tamaño y relevancia, se ubicaban sobre los distintos arroyos hacia el este y sur: el Tagarete era atravesado por las alcantarillas de la torre del Oro, de la (puerta) Nueva, del Ganado, de San Bernardo y de las Madejas; y por otras no incluidas en la leyenda, aunque sí en la del Infante Don Carlos: la de la Muralla, de la puerta de Jerez, de Rompida, de Buron, y de la Fuente del Arzobispo. Sobre el arroyo Tamarguillo se situaban las alcantarillas de Eritaña y otra identificada como la de la Casa de la Cera en el plano del Infante Don Carlos. Existían más alcantarillas, en zonas inundables, como la de San Sebastián en el prado homónimo, o la de la Enramadilla, en el plano del Infante Don Carlos, más otras sin nombre; y en Triana la de los Ciegos, sobre la antigua Cava y cercana a la parroquia de la $\mathrm{O}$. Todas ellas fueron sucumbiendo al perder su función tras posteriores transformaciones hidráulicas.

\subsubsection{Huertas}

El conjunto histórico de Sevilla estaba envuelto por un amplio cinturón de prados, dehesas y huertas que marcaban su carácter agrícola y ganadero. Los prados eran extensos terrenos públicos donde crecía el pasto natural para el ganado. Los dos más importantes eran el prado de San Sebastián y el de Santa Justa. La misma función cumplían las dehesas, entre las que destacó la de Tablada, al sur del arroyo Tamarguillo y el meandro de los Gordales del Guadalquivir. Las huertas, de carácter privado, solían tener tamaño pequeño y cultivos variados. Los huertos estaban en un primer cinturón más próximo a la muralla, incluyendo naranjales, mientras que los cultivos de secano de la triada mediterránea -cereal, viñedo, olivar- estaban en una segunda y tercera corona que la rodeaba, situados al este, tras el Tamarguillo. Las huertas estaban vinculadas a la disponibilidad de agua, abundante en el sector norte, frente a las puertas de la Macarena, de Córdoba y del Sol; en el este, en torno al acueducto y en el oeste, en la Vega de Triana, situada en la primera terraza del río Guadalquivir, un espacio inundable y por ello tremendamente fértil.

Son muy valiosas las abundantes referencias toponímicas sobre huertas incluidas en la leyenda. En el sector oriental se refleja un amplio listado: de San Telmo, la Ysabela [sic] (Isabela), de Pereo (hacia 1850 llamada Mariana), de San Sebastián, de Pedroso, del Rastro, de Tabladilla, de la Moraleja, de San José, del Rey, del Retiro, de espanta Perrillos, de espanta Perros, de S. Rafael, de las Madejas, del Judío, de la Ciñuela, de la Cruz, de S. Salvador Chica, de S. Salvador 
Grande, de las Palmas, del Pilar, de San Ygnasio [sic] (Ignacio), del Cardenal, del Cortijo, del Cortijuelo, de San Agustín, de S. Roque, de los Toribios, de San Benito, de Rueda, del Pino, del Ciego, de los Muertos, de las tres Puertas, de los Muñones, del Prado, de la Trinidad, de Pajarito, de los Miradores, de Fontanar o Fontanal, del Saltillo o Saetillo, de la Mulatilla, de Sampajes (San Pagés), de la Alcantarilla rompa (rota), de San Gregorio, de Santa Maria, de Navojordo (Navo gordo o Árbol Gordo), de Cirneo bajo (Cisneo), de Cirneo bajo (Cisneo), del Castillo, de Carcajea, de San Francisco, de la Bartola (Barzola), del Hierro, Pintada, de la Llesca (Yesca), del Cajilon (Cagilon), de Capuchinos, de los Portugueses, del Soldado, del basurero, del Sapote (Zapote), del Rosario, de San Clemente, de Constanza, de la Ymajen [sic] (Imagen), del hospital de la Sangre, de Serrano, de la Cigarra, de Cerez (Cerezo), de Almenarilla o Almendrilla, de S. Gil, de Palmilla, de la Colecita, de la Cordovesa [sic], y de los Gatos.

Y en Triana, en el sector occidental, se relacionan estas otras huertas: de los Remedios, de la Victoria, de Molina, de D. Antonio Tolesano, del Polvorista, de las Cañas, de Cortinas, de los Mártires, de Calle TroIla, Perdida, de Marianillo, Abandonada, de Ardila, de Juan Duran, del Canónigo, Jardín, del Jardinillo, de la Torrecilla, del Mariscal, de S. Luis, de los Muñones, y El Cortijo.

FIGURA 7

ELEMENTOS ESTRUCTURANTES DE LA PERIFERIA URBANA DE SEVILLA A PRINCIPIOS DEL SIGLO XIX

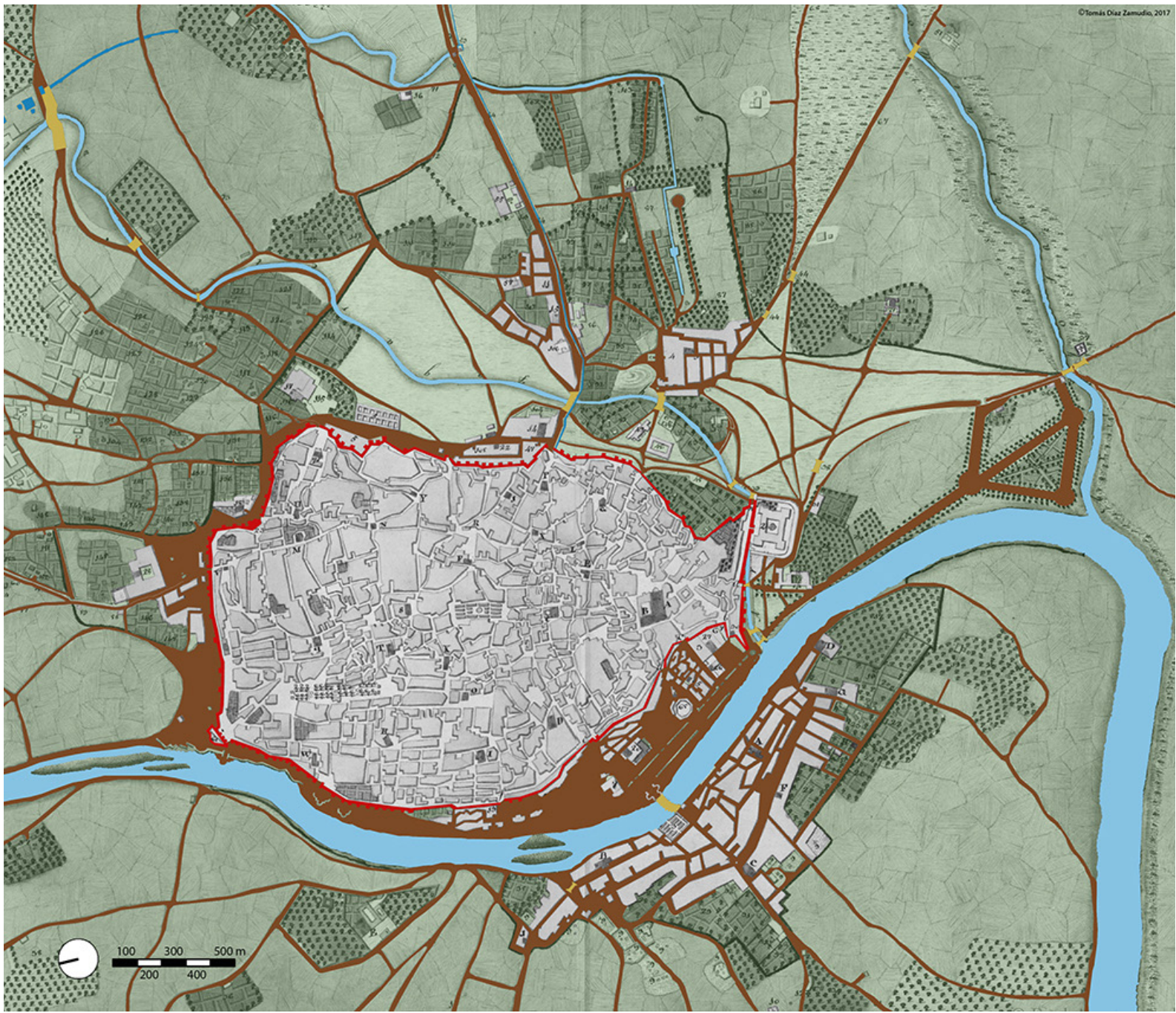

Fuente: Elaboración propia, 2017. Esquema dibujado sobre el plano de Spínola de 1827. Leyenda: Muralla y puertas (rojo), Caminos (marrón), Red hidrográfica (azul), Puentes y alcantarillas (ocre), Huertas (verde claro). 
Muchas se transformaron en ciudad con loteos y crecimientos no ordenados, o en operaciones urbanísticas de los siglos XX y XXI. A veces su toponimia se conserva aunque no quede rastro de ellas, dando nombre a barrios (huerta de Santa Teresa, del Rey, de la Salud, del Pilar...) y calles (huerta del Sol, de la Fontanilla, de la Papachina...) mientras otras se han conservado parcialmente (huerta de Miraflores, del Retiro -hoy Jardines de Murillo y Paseo de Catalina de Ribera-, Buhayra...).

\subsection{Arrabales}

Los arrabales más importantes eran: Triana, San Bernardo, San Roque, La Calzada, Macarena, Humeros, Cestería, y Carretería. Entre ellos destaca el popular arrabal de Triana al otro lado del río, con entidad propia, y por ello en la leyenda se indican los elementos más notables de la "urbe" por un lado, y de Triana por otro.

Algunos de estos barrios extramuros existían ya antes de la conquista cristiana de 1248: es el caso de Triana, la Macarena y Benialofar (San Bernardo). Ninguno de ellos fue consecuencia del desbordamiento de la ciudad, ya que el inmenso recinto amurallado almohade no llegaría a colmatarse prácticamente hasta el siglo XIX. La razón del desarrollo de cada uno de estos barrios hay que buscarla en su funcionalidad: Triana tenía su origen en una antigua alquería andalusí, el desplazamiento del río Guadalquivir hacia el oeste y la construcción del puente de barcas en 1171, propiciaron su conversión en arrabal; Macarena, San Roque, La Calzada y San Bernardo surgieron con las huertas, y también vinculados a la actividad ganadera y matadero ligado a los prados inmediatos; y los demás, Cestería, Carretería y los Humeros, estaban asociados al desarrollo del puerto, con un notable crecimiento a partir del siglo XVI gracias al monopolio del comercio con América.

\subsection{Elementos arquitectónicos singulares o hitos}

En el plano de Spínola de 1827 se incluyen las edificaciones religiosas (conventos, monasterios, iglesias, ermitas, y capillas), agrarias (cortijos, haciendas y molinos de agua), militares (cuarteles), fabriles, hospitalarias, funerarias (cementerios) ventas, lavaderos, otros edificios (plaza de toros, mercados...) y espacios públicos.

\subsubsection{Religiosos}

Los edificios de carácter religioso, iglesias, ermitas y capillas, más monasterios y conventos, mayoritariamente masculinos, eran abundantes en la periferia urbana, según refleja la propia leyenda. En el sector oriental destacan las parroquias de San Bernardo, y de San Roque, que dan nombre a sus arrabales; las capillas de San Sebastián, de Ntra. Sra. de los Ángeles, de San Hermenegildo, de Ntra. Sra. de la Piedad, del Stmo. Cristo de las Tres Necesidades, de Ntra. Sra. del Rosario, y de la Concepción; y el humilladero de la Cruz del Campo, junto al que se encontraba la ermita de la Soledad. En cuanto a conventos se citan los de Sto. Domingo de Portaceli (Dominicos), de San Agustín (Agustinos), de San Benito de Calatrava [sic] (la Calzada) (Benedictinos), de Santa Teresa (Carmelitas Descalzos), de Trinitarios Calzados (de la Santísima Trinidad), de Capuchinos (de Santa Justa y Rufina), de San Laureano (Mercedarios Calzados), y de Ntra. Sra. del Pópulo (Agustinos Descalzos).

Además, en Triana destacan tanto las parroquias de Santa Ana, y Ntra. Sra. de la O, como las capillas de Los Mártires y El Patrocinio; más los conventos de San Jacinto (Dominicos), de Los Remedios (Carmelitas Descalzos), de la Cartuja (de Sta. María de las Cuevas), de Monjas Mínimas (de Consolación), y de La Victoria (Mínimos).

Hoy se conservan gran parte de dichas capillas y parroquias, que han mantenido un uso continuado, a veces renovadas o reconstruidas. Sin embargo, los recintos monacales y conventuales no han corrido la misma suerte (Pérez, 1996). Tras las diversas desamortizaciones del XIX solo algunos se mantienen con su mismo uso (Capuchinos, Monjas Mínimas en Triana y San Jacinto reconstruido a principios del siglo $\mathrm{XX}$ ); otros fueron transformados (La Cartuja y San Laureano); o parcialmente derribados (San Agustín y San Jerónimo de Bellavista, no incluido en el plano); en otros casos solo se salvaron sus templos (San Benito de la Calzada, Santísima Trinidad, San Jacinto y Los Remedios); y algunos fueron demolidos (Santo Domingo de Portaceli, Santa Teresa, Nuestra Señora del Pópulo y La Vitoria).

\subsubsection{Agrarios}

Los cortijos y haciendas eran muy numerosos en el área periurbana. Estaban situados tras las huertas, en el segundo anillo de cultivos de secano. Debido a su localización más alejada y a la dimensión y escala del plano, quedaron fuera del área representada, salvo la Casa de la Cera, propiedad del británico Nathan Wetherell. En la leyenda del plano del Infante Don Carlos aparecen también el cortijo de Maestre Escuela y el de la Corza. Además se aprecian arquitecturas domésticas de menor escala para actividades 
agropecuarias (casas, albercas, norias...), que por su reducido tamaño no figuran en la leyenda del plano.

\subsubsection{Militares}

La implantación de instalaciones militares ubicadas en el entorno de la ciudad surgiría desde la Edad Media y se incrementaría a partir del siglo XVI. Las más importantes se situaron en las inmediaciones de la muralla: el cuartel de Carabineros o de Caballería hacia la puerta de la Carne; y el cuartel de San Roque para inválidos cerca de la puerta de Carmona. También cabe mencionar la posterior plaza de Armas, antes conocida como Campo de Marte, entre la puerta de Triana y la puerta Real, que estaba en proceso de configuración. Algunas de estas instalaciones, de carácter fabril, se incluyen en el siguiente subapartado.

\subsubsection{Fabriles}

Las fábricas se situaron en la periferia por falta de espacios interiores en la ciudad y por otras razones (peligrosidad, polución, logística de abastecimiento y distribución...). La mayoría, construidas o reformadas en el siglo XVIII, se concentraron en lo que se podría denominar como primer cinturón de la ciudad, salvo la fábrica de curtidos de Wetherell, más alejada, pues reutilizó el antiguo convento de San Diego, al igual que ocurrió en décadas sucesivas con otros conventos extramuros como la Cartuja y San Jerónimo.

Las más importantes reflejadas en el plano eran de iniciativa o protección estatal: Real Fábrica de Tabacos, Real Maestranza de Artillería, Real Fundición de Artillería, Real Fábrica de Salitre, Real Aduana, Reales Atarazanas de Azogues, Reales Almacenes de madera de Segura, Fabrica de San Diego de Curtidos. En Triana destaca la presencia de las Reales Almonas o fábrica de Jabón, y numerosos hornos de ladrillos en la Vega trianera, propios de un lugar con una dilatada tradición alfarera.

\subsubsection{Hospitalarios}

Los hospitales se ubicaban fuera del perímetro urbano por cuestiones higiénicas y por falta de espacio. En la leyenda se indica el de la Sangre (de las Cinco Llagas de Nuestro Redentor, o Central cuando aglutinó cinco hospitales en 1837) frente a la puerta de la Macarena, y el de la Caridad ocupando parte de las atarazanas medievales; mientras que el de San Lázaro quedaría fuera del área dibujada en este plano.

\subsubsection{Funerarios}

Las epidemias que asolaron Sevilla, junto con las nuevas medidas higiénicas, propiciaron en los inicios del XIX la aparición de cementerios extramuros. A mediados de siglo se proyectó un único camposanto al norte de la urbe, el de San Fernando, obra del arquitecto municipal Balbino Marrón en 1852, en sustitución de los cuatro existentes: el de San Sebastián de 1827, junto a la ermita homónima; el cementerio para Pobres, junto a la venta y alcantarilla de Eritaña; el de San Lázaro, junto al hospital del mismo nombre, germen del actual de San Fernando (sólo reflejado en el plano del Infante Don Carlos); y el de Triana en las cercanías de la huerta de la Torrecilla.

\subsubsection{Ventas}

En época de los Reyes Católicos muchas ventas ya se emplazaban junto a los principales caminos (Diago y Ladero, 2009, p. 353). En la leyenda se reseñan las siguientes: la de Pereo, de Eritaña, de la Cruz del Campo, de los Escalones, de la Concepción, y de los Gatos, célebre gracias a Gustavo Adolfo Bécquer; y en la leyenda del plano de 1828-30, la de la Laguna de los Patos. La mayoría se perdieron por falta de uso.

\subsubsection{Lavaderos}

Los lavaderos, de lana según la leyenda del plano del Infante Don Carlos, eran instalaciones de gran tamaño, situados en las principales vías de acceso a la ciudad, en lugares con agua para desgrasar, limpiar y tratar la lana proveniente en su mayoría de Extremadura y destinada a la exportación. En 1827 existían al menos cinco (Miñano, 1827, p. 261), ubicados en enclaves al este y norte de Sevilla: el de la Cruz del Campo (Larruga, 1795, p. 275), de Bertendona, y de Texas [sic] (Tejas) Coloradas; más los lavaderos de los Portales, de las Palmas y de lana basta, según la leyenda del plano de 1828-30. Este último, de menor tamaño, se situaba al noroeste de la cerca, junto al Patín de las Damas y el husillo del Taco ${ }^{29}$. Hoy todos ellos han desaparecido con la expansión de la ciudad.

\subsubsection{Otros edificios y espacios públicos}

Finalmente cabe citar otros elementos que aparecen en la leyenda: el Real Colegio de San Telmo, las torres del Oro y de la Plata, la plaza de Toros, el matadero y el mercado de abastos de Triana, denominado como Plaza Nueva. Asimismo, se reflejan algunas intervenciones urbanas en espacios públicos: el paseo del Abanico con su fuente, el Jardín Nuevo o Paseo de las Delicias 
conocido como Delicias de Arjona, la Alameda de la Bellaflor, el paseo del Patín de las Damas con sus malecones y embarcaderos junto al río, El Blanquillo o Patín de las Damas adyacente a la puerta de la Barqueta, y los muelles en ambas riberas del río. El Salón de Cristina no se delineó, pues aún no se había proyectado en 1827.

\section{CONCLUSIONES}

El plano inédito de 1827 de Manuel Spínola de Quintana (1770-1833) fue el primero de origen no militar que además del interior urbano representó la periferia de Sevilla. Ello sería consecuencia del creciente interés e importancia de este espacio, que había tenido hasta entonces un carácter eminentemente agrario y que tras iniciarse el derribo de la muralla fue ocupado por la expansión de la ciudad. Así por primera vez se ofrecía una descripción sistemática y rigurosa, más completa que la aportada por las vistas y planos existentes hasta entonces (Díaz y Gámiz, 2018), incorporando datos minuciosos y detallados.

En cuanto a la finalidad del plano, éste no obedecía a intereses militares, sino que respondía a la necesidad de visualizar y conformar un sistema de

FIGURA 8

ELEMENTOS SINGULARES O HITOS ARQUITECTÓNICOS DE LA PERIFERIA URBANA DE SEVILLA A PRINCIPIOS DEL SIGLO XIX

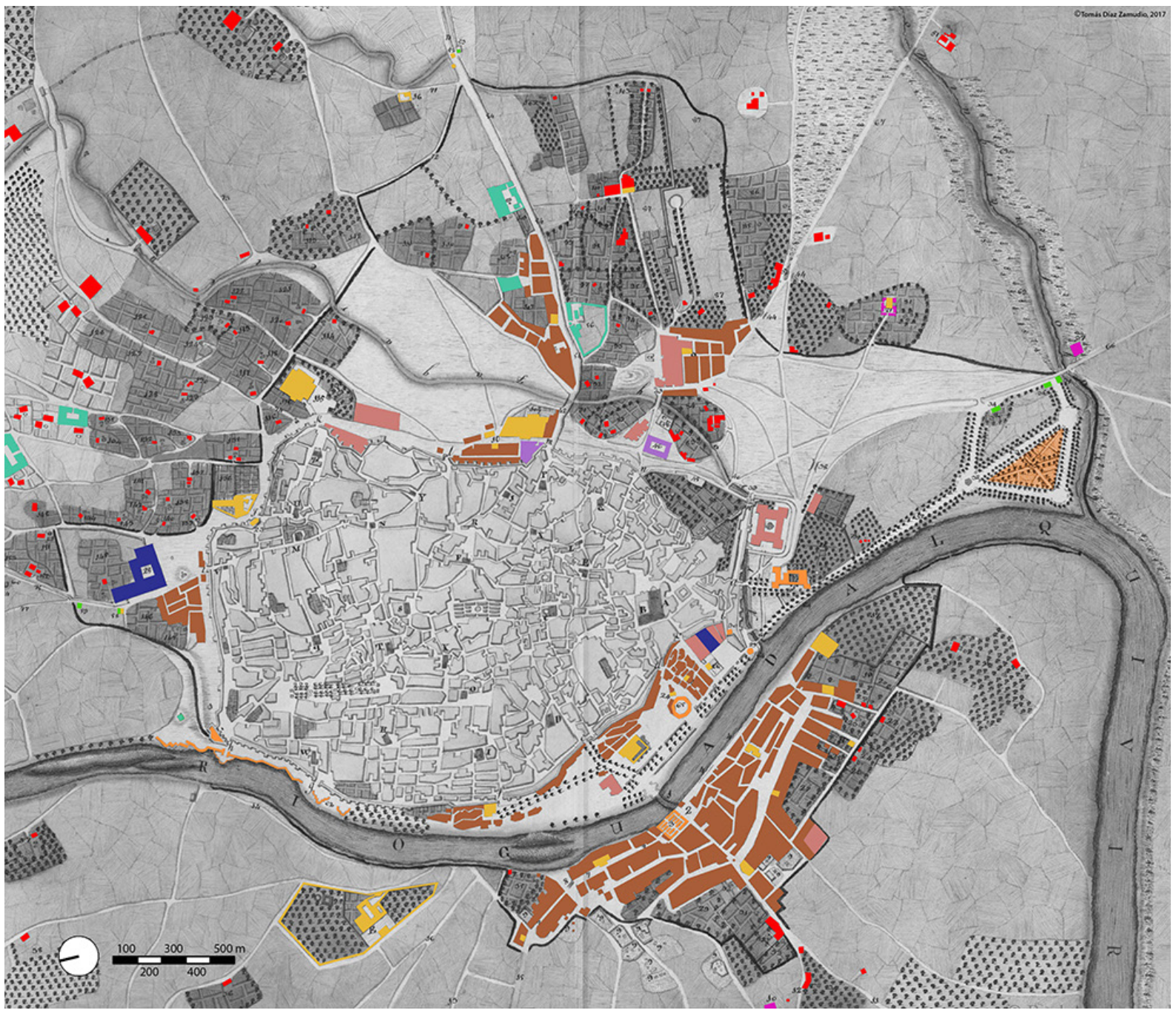

Fuente: Elaboración propia, 2017. Esquema dibujado sobre el plano de Spínola de 1827. Leyenda: Arrabales (marrón), Religiosos (ocre), Agrarios (rojo), Militares (lila), Fabriles (rosa), Hospitalarios (azul), Funerarios (magenta), Ventas (verde), Lavaderos (turquesa), otros edificios y espacios públicos (naranja). 
control aduanero adecuado para los reimplantados "Derechos de Puertas". Por ello se reflejan los fielatos o cajones de fieldad y un perímetro fiscal no necesariamente coincidente con la muralla, representado con una línea azul, para la recaudación de impuestos destinados a las Rentas Reales conforme al Real Decreto de 16 de febrero de 1824. Esa misma finalidad tuvieron otros planos de similares características, también dibujados por Spínola en aquellos años, de las poblaciones más importantes de la provincia de Sevilla: Utrera, Carmona, Marchena, Morón, Osuna y Écija. Éstos pueden considerarse como destacados precedentes de la minuciosa cartografía catastral española, que incluyó mayor nivel de detalle que otros planos elaborados hasta entonces. Por ello, este plano inédito de Sevilla y su periferia urbana debe considerarse como una destacada referencia para la historia de la cartografía urbana de España.

Este documento gráfico refleja intervenciones urbanas significativas que se acometieron bajo el mandato del asistente José Manuel de Arjona (1825-1833). Fuera de la muralla destacan las operaciones de embellecimiento con alamedas o paseos arbolados ajardinados en Las Delicias y el Salón de Cristina, ejecutados bajo la dirección del Arquitecto Mayor Melchor Cano y la tutela del profesor de agricultura y botánica Claudio Boutelou, que pueden considerarse como primeras actuaciones en la expansión de la ciudad hacia el sur. También se reflejan proyectos recientes o en marcha en aquel momento, como el cementerio de San Sebastián, el mercado de Triana o la plaza de Armas.

Por otra parte se ha constatado la estrecha relación de este plano con otros dos de aquellos años que son muy similares. Uno, depositado en el Archivo Municipal de Sevilla, datado aquí hacia 1828-30 (hasta ahora se fechaba hacia 1827-30) atendiendo a las intervenciones que conformaron el Salón de Cristina, según otro plano de Melchor Cano de 1828, cuyo autor fue también Manuel Spínola, y es conocido como el del Infante Don Carlos. El otro, fechado en 1839, fue dibujado por Manuel Galiano Parra, cuya autoría se ha corregido gracias a esta investigación. Según un documento inédito localizado en la Real Sociedad Económica de Amigos del País, Spínola entregó un plano de Sevilla y su entorno a dicha Institución, hoy en paradero desconocido. Quizás podría tratarse del plano aquí estudiado o tal vez una copia del mismo.

En cuanto a los contenidos representados en el plano, debe indicarse que desde inicios del XIX los elementos estructurantes de la periferia urbana, por su escala, han sido profundamente transformados o ya no existen. Éstos eran esencialmente de carácter público, dependientes del cabildo municipal que se encargaba de su mantenimiento, en ocasiones con el apoyo del Estado. Se trata de las murallas y puertas, los caminos, los Caños de Carmona (acueducto) y los prados, entre otros.

Por otro lado, los elementos singulares representados han tenido distinta suerte: la pérdida de importancia de ciertos hitos, muchas veces se debió a la falta de un adecuado uso. Debe considerarse que la mayor parte de estos edificios eran de carácter privado, excepto hospitales y edificios religiosos (monasterios, conventos, iglesias y capillas) que tenían asociados huertas. Resulta llamativo que en el sector oriental desaparecieron la mayoría de conventos, en un largo proceso que se inició con la invasión napoleónica -al reutilizarse con fines militares- y que continuó con las sucesivas desamortizaciones del $\mathrm{XIX}$, que dieron al traste con gran parte de este rico patrimonio arquitectónico y religioso.

Otros elementos singulares en la periferia urbana eran de propiedad estatal y militar como los cuarteles y un considerable número de fábricas. Precisamente éstos son los que mejor se han conservado hasta la actualidad.

Llaman especialmente la atención los lavaderos y su inclusión en la leyenda del plano, que ilustra la importancia que tuvieron. Éstos desaparecieron con los nuevos crecimientos de la ciudad, evidenciando la estrecha relación entre uso y conservación.

Un caso singular son las ventas, que perdieron su razón de ser dentro de la ciudad consolidada y en su mayoría no perduraron. Destaca el caso de la famosa venta de los Gatos que aún se mantiene en pie, pero con un futuro incierto.

Además, los cementerios fueron objeto de interés municipal y siguiendo la Real Cédula de 3 de abril de 1787 se situaron extramuros, inicialmente en cuatro localizaciones, para posteriormente unificarse en un único camposanto aún hoy en funcionamiento, el de San Fernando.

Finalmente, puede afirmarse que en este plano es fácil reconocer el espacio extramuros de Sevilla desde la Edad Media hasta principios del siglo XIX, gracias a la abundante información que aporta, que no se encuentra en otras fuentes gráficas o literarias, y por ello es un documento del mayor interés para la historia de la ciudad hispalense. Se trata de una especie de palimpsesto que permite distinguir distintas capas 
superpuestas que fueron transformando un espacio agrario y de recreo, que incluía actividades artesanales y vinculadas con el abastecimiento de la ciudad desde, al menos, la Edad Media. Y que a lo largo de la Edad Moderna evolucionó, haciéndose más complejo, con la incorporación de elementos de carácter religioso, industrial y militar, conservando la herencia rural en las zonas más alejadas de la ciudad, cada vez de forma más anecdótica a medida que avanza el tiempo.

\section{NOTAS}

1. Muy Noble, Muy Leal y Muy Heroica.

2. Signatura C-Cuadros-11_Sevilla.

3. "Fachada de los cinco arcos con que mi proyecto general de 30 de Marzo de 1784 propuse romper el testero de la Torre del Oro, dejando en lo alto el debido paso a ésta desde los Reales Alcázares, y a su costado dos casas para la Capitanía de este Puerto y fielato de su Real Aduana [...] Sevilla. Febrero 1809. Manuel Zintoria". Patrimonio Nacional, Archivo General de Palacio, Sección Planos, Signatura 6123.

4. Ciertos autores no indican la fecha exacta de la demolición de la coracha (Braojos, 1976; Marín y del Pozo, 1986, p. 82; Suárez, 1986, p. 202) o la datan erróneamente en 1830 (Morales, 2013, p. 690).

5. "[...] expediente que principia en el año 1821, sobre la demolición de las casas el sitio de la Torre del Oro [...]". Archivo Municipal de Sevilla, Sección VI, Tomo 110, número 1.

6. Archivo Municipal de Sevilla, Sección VI, Tomo 89, número 60.

7. Nacido en Osuna (Sevilla), ocupó diferentes cargos públicos y llegó a ser Superintendente General de Policía del Reino en Madrid, hasta que fue designado Asistente de Sevilla. Gracias a su eficaz gestión, se superaron décadas de estancamiento urbanístico debidas a la penosa situación financiera (Braojos, 1976).

8. Casa de subastas Fernando Durán, Madrid, 5 de octubre de 2010, lote $n$ o 356. Adquirido por iniciativa de D. Gonzalo Anes, que fue Director de la Real Academia de la Historia (Manso, 2012b, p. 5).

9. Así aparece su nombre en el expediente de información de legitimidad y limpieza de sangre, para su entrada en el Colegio de San Telmo de Sevilla
De este modo, el plano inédito de Sevilla de Manuel Spínola de 1827, permite poner en valor elementos clave de la periferia urbana, que fue radicalmente transformada por crecimientos urbanos posteriores. Por todo ello, cabe esperar que las aportaciones de esta investigación, faciliten la recuperación de la memoria y la identidad perdida en dicho lugar, englobando intereses comunes a la geografía, la historia, el urbanismo y la arquitectura.

(Archivo Histórico de la Universidad de Sevilla, 1784, p. 1).

10. Archivo Histórico de la Universidad de Sevilla, 1772-1784.

11. En Junta extraordinaria del día 5 de Julio de 1827 se acordó nombrarlo socio facultativo en Matemáticas tras la entrega de un plano de Sevilla a dicha institución. Real Sociedad Económica de Amigos del País de Sevilla, libro de Actas de las Juntas, no 9, 1824-1836, p. 81 recto y verso.

12. "Art. 10. Habrá derechos de puertas en las capitales de Provincia [...] como se establecieron en el años de mil ochocientos diez y siete: los habrá también en los pueblos que tenga tres mil vecinos ó quince mil habitantes, los cuales se designarán más abajo. [...] Art. 20. [...] Sevilla: [...] Carmona. Marchena. Ecija. Moron de la Frontera. Osuna. Utrera [...]"

13. Sevilla "Está dividida en 15 partidos que son: el de la capital, el de Carmona, Ecija, Marchena, Osuna, Estepa, Utrera, San Lucar la Mayor, Aznalcazar, Constantina, Aracena, Fregenal, Niebla, Huelva y Ayamonte" (Miñano, 1827, p. 233).

14. Según la casa de subastas Fernando Durán mide $41 \times 73 \mathrm{~cm}$.

15. La vara de Burgos, también conocida como vara de Castilla, equivale a 3 pies y 0,835905 m. Real Orden de 9 de diciembre de 1852.

16. Para su valoración, se ha realizado una superposición con un plano actual usando el programa informático Autocad, tomando como referencia el río y la muralla

17. A Su Alteza Real Y Serenísima El Señor Infante Don Carlos María Isidro de Borbón.

18. Signatura II-5-2. Existen discordancias respecto a su dimensión: 63 x 113 cm (Collantes de Terán, 
1970, p. 28) o $80,5 \times 117 \mathrm{~cm}$ (Rodríguez, 2007, p. 282). Se reparó en 2006 para la exposición "La Sevilla de Richard Ford (1830-1833)" de la Fundación El Monte de Sevilla.

19. Signatura 31-E-3. Antes el Instituto Geográfico Nacional indicaba que el autor era Manuel Galiana, del cual no se tiene información, debido a la confusión que genera la tipografía de su firma. Este dato fue corregido, gracias a este trabajo, y hoy se atribuye a Manuel Galiano Parra, que fue maestro de obras cuando ejecutó el plano y posteriormente arquitecto municipal de Sevilla (Archivo de la Real Academia de Bellas Artes de San Fernando de Madrid, legajo 2-17-3, 1836; legajo 2-11-4, 1841).

20. Algunos monasterios y conventos extramuros cambiaron de uso: el de San Agustín a prisión; el del Pópulo a cárcel; el de la Cartuja a fábrica de loza; el de San Jerónimo de Buenavista a fábrica de vidrios...

21. Su inauguración coincidió con la fecha del plano de Spínola: 1 de mayo de 1827 (Suárez, 1986, p. 58-59).

22. Oficio leído públicamente en el cabildo celebrado el 28 de mayo de 1827, según consta en las Actas Capitulares. Archivo Municipal de Sevilla, Sección X, Rollo 372, 2a Escribanía, p. 93 recto.

23. "Este plano contiene todos los barrios extramuros, caminos, huertos, arboledas etc., hasta el término de Santiponce, Camas, Tomares, San Juan de Aznalfarache y Dos Hermanas y por la parte de levante el arroyo Tamarguillo, hasta la huerta de los Ingleses y el Tagarete hasta la del Tesorero; al Norte se extiende hasta pasado San Lázaro [...] Sevilla 26 de mayo de 1827".

24. “El Sr. Rodriguez presentó el plano de Sevilla triana arrabales y su termo. levantado pr. el Sor. D.

\section{BiBLIOgRAFÍA}

Algarín Vélez, I. (2000). Método de transcripción y restitución planimétrica. Su aplicación al estudio del plano de Sevilla de 1771 mandado levantar por disposición del Sr. D. Pablo de Olavide, asistente de esta ciudad. Sevilla, España: Universidad de Sevilla y Fundación Focus.

Antigüedad del Castillo-Olivares, M. D. (1990). El arquitecto Melchor Cano y la teoría de la ciudad. Espacio, Tiempo y Forma, Serie VII, Historia del Arte, t.3, 417-439.
Manl. Espinola Catedratico del RI. Colegio de S. Telmo, el qe. habiendo merecido la aprobación dela Junta, se acordó nombrarlo facultativo en Matemáticas." Real Sociedad Económica de Amigos del País de Sevilla, libro de Actas de las Juntas, no 9, 1824-1836, p. 81.

25. Manuel Spínola entregó un plano de Sevilla (que no se ha podido localizar) a la Real Sociedad Económica de Amigos del País de Sevilla a través de Gabriel Rodríguez, socio facultativo y experto en matemáticas, según consta en Junta extraordinaria de dicha institución del día 5 de Julio de 1827.

26. El 29 de marzo de 1830 se promulgó la Pragmática Sanción que anulaba la Ley Sálica (1713) desplazando al propio Infante, siempre que su hermano el monarca Fernando VII tuviera descendencia. Dichos pronósticos se confirmaron con el nacimiento de la futura Isabel II el 10 de octubre de ese año, que provocarían el inicio de las guerras carlistas.

27. "Tiene 166 torreones y 15 puertas o postigos." (Miñano, 1827, p. 243).

28. Se recoge la denominación original que aparece en la leyenda del plano de Spínola de 1827 para todos los elementos designados en los siguientes subapartados.

29. Este lavadero aparece dibujado en el plano manuscrito del proyecto de defensa contra las inundaciones del río, Mapa del Guadalquivir y sus márgenes, desde la Puerta de la Barqueta al Patín de las Damas, firmado por el Maestro Mayor de Obras de Sevilla, el arquitecto Pedro Juan Laviesca de la Torre, ejecutado hacia 1743. Archivo Municipal de Sevilla, signatura SAHP 3098.

Archivo Histórico de la Universidad de Sevilla. (1784). Expediente de información de legitimidad y limpieza de sangre de Manuel Espínola y Quintana, para la entrada en el Colegio de San Telmo de Sevilla, Libro 257, fol. 216-227. Sevilla, España.

Archivo Histórico de la Universidad de Sevilla. (17721784). Expediente de don Manuel Espínola y Quintana, Libro de recepción y salida de colegiales del Real Colegio Seminario de San Telmo, Libro 279, fol. 265. Sevilla, España. 
Banda y Vargas, A. (de la). (1972). El urbanismo sevillano en el siglo XIX. En Historia del urbanismo seviIlano (pp. 133-165). Sevilla, España: Real Academia de Bellas Artes de Santa Isabel de Hungría y CSIC.

Braojos Garrido, A. (1976). D. José Manuel de Arjona, Asistente de Sevilla, 1825-1833. Sevilla, España: Delegación de Cultura del Ayuntamiento de Sevilla.

Carriazo y Arroquía, J. de M. (1951). Las murallas de Sevilla. Archivo Hispalense, t. 25, nำ 48, 9-80.

Castañón Álvarez, J. C. y Puyo, J. Y. (2008). La cartografía realizada por el ejército napoleónico durante la guerra de la Independencia. En F. Quirós Linares y J. C. Castañón Álvarez (dirs.), Madrid 1808. Guerra y territorio. Mapas y planos 1808-1814 (pp. 67108). Madrid, España: Museo de Historia.

Centro de Documentación de Defensa (2008). Cartografía de la Guerra de la Independencia. Madrid, España: Ministerio de Defensa \& Ollero y Ramos Editores.

Collantes de Terán y Delorme, F. (1970). Patrimonio monumental y artístico del Ayuntamiento de SeviIla. Sevilla, España: Ayuntamiento de Sevilla.

Collantes de Terán Sánchez, A. (1977). Sevilla en la Baja Edad Media: la ciudad y sus hombres. Sevilla, España: Ayuntamiento de Sevilla.

Cortés José, J., García Jaén, M. J. y Zoido Naranjo, F. (1992). Planos de Sevilla. Colección histórica (17711918). Sevilla, España: MAD y Ayuntamiento de Sevilla.

Cuenca Toribio, J. M. (1976). Historia de Sevilla. Del Antiguo al Nuevo Régimen. Sevilla, España: Universidad de Sevilla.

Diago Hernando, M. y Ladero Quesada, M. A. (2009). Caminos y ciudades en España de la Edad Media al siglo XVIII, España Medieval, no 353, vol. 32, 347-382.

Díaz Garrido, M. (2010). Triana y la orilla derecha del Guadalquivir. Evolución de una forma urbana desde sus orígenes hasta mediados del siglo XX. Sevilla, España: Fundación Focus-Abengoa y Universidad de Sevilla.

Díaz Zamudio, T. y Gámiz Gordo, A. (2018). Views of Sevilla environs until 1800. En C. Marcos (Ed.), Graphic Imprints. The Influence of Representation and Ideation Tools in Architecture (pp. 1177-1188). Cham, Suiza: Springer. https://doi. org/10.1007/978-3-319-93749-6_97
Fajardo de la Fuente, A. (2016). Una primicia cartográfica: Los planos manuscritos de las principales ciudades de la Intendencia de Sevilla mandados levantar por el Asistente Arjona (1825-27). Cuadernos de los Amigos de los Museos de Osuna, no 18, 37-44.

Falcón Márquez, T. (1993). La Torre del Oro en el siglo XIX: documentos inéditos. Laboratorio de Arte, no 6, 221-244.

Ford, R. (2008). Manual para viajeros por España y lectores en casa. Andalucía. Madrid, España: Biblioteca Turner.

Gámiz Gordo, A. y Díaz Zamudio, T. (2019). Sevilla extramuros en el siglo XVI: tres vistas del Civitates Orbis Terrarum. Boletín de la Asociación de Geógrafos Españoles, no 80, 2592. doi: https://dx.doi. org/10.21138/bage.2592

González Cordón, A. (1985). Vivienda y ciudad. Sevilla 1849-1929. Sevilla, España: Centro Municipal de Documentación Histórica del Ayuntamiento de Sevilla.

Herrera Dávila, J. (ed.) (1832). Guía de Forasteros de la ciudad de Sevilla. Sevilla, España: Diario de Comercio.

Larruga y Boneta, E. (1795). Memorias políticas y económicas. Sobre los frutos, comercio, fábricas y minas de España. Con inclusión de los Reales Decretos, Órdenes, Cédulas, Aranceles y Ordenanzas expedidas para su gobierno y fomento. Minas y producciones de la provincia de Extremadura, Tomo XXXVII. Madrid, España: Antonio Espinosa.

Manso Porto, C. (2012a). La colección cartográfica y documental de la Real Academia de la Historia sobre la Independencia de Nueva España. En Ciclo de conferencias: Madrid y el mundo de la independencia americana. Madrid, España: Instituto de Estudios Madrileños y CSIC.

Manso Porto, C. (2012b). Las colecciones del Departamento de Cartografía y Artes Gráficas en la Biblioteca Digital de la Real Academia de la Historia. Revista Catalana de Geografía, IV época, vol. XVII, no 46, 1-21.

Manso Porto, C. (2013). Spínola de Quintana, Manuel. En Diccionario Bibliográfico Español. Volumen XLVII: De "Solé i Sabarís" a "Tolosa Latour" (pp. 302-303). Madrid, España: Real Academia de la Historia.

Marín de Terán, L. y Pozo Serrano, A. (del). (1986). Los pavimentos: un fragmento de la historia urbana de Sevilla. Sevilla, España: Ayuntamiento de Sevilla. 
Martínez Shaw, C. y Alfonso Mola, M. (2009). España en el comercio marítimo internacional (siglos XVII$X(X)$, Quince Estudios. Madrid, España: UNED.

Miñano y Bedoya, S. (de). (1827). Diccionario geográfico-estadístico de España y Portugal, Tomo VIII. Madrid, España: Imprenta de Pierart-Peralta.

Morales Martínez, A. J. (2013). Un episodio en el derribo de las murallas de Sevilla. Laboratorio de Arte, no 25, 689-700.

Pérez Cano, M. T. (1996). Patrimonio y ciudad. El sistema de los conventos de clausura en el Centro Histórico de Sevilla. Génesis, diagnósticos y propuesta de intervención para su recuperación urbanística. Sevilla, España: Fundación Focus y Universidad de Sevilla.

Quirós Linares, F. (2009). Las ciudades españolas en el siglo XIX. Gijón, España: Trea.

Rodríguez Barberán, F. J. (1996). Los cementerios en la Sevilla contemporánea. Análisis histórico y artístico (1800-1950). Sevilla, España: Diputación de Sevilla.

Rodríguez Barberán, F. J. (ed.) (2007). La Sevilla de Richard Ford (1830-1833), catálogo de la exposición. Sevilla, España: Fundación El Monte.
Seta, C. (de) y Le Goff, J. (1991). La ciudad y las muraIlas. Madrid, España: Cátedra.

Suárez Garmendia, J. M. (1986). Arquitectura y Urbanismo en la Sevilla del siglo XIX. Sevilla, España: Diputación Provincial de Sevilla.

Suárez Garmendia, J. M. (1999). En torno al extramuros de Sevilla, el plano de 1836. Laboratorio de Arte, nㅇ 12, 345-354.

Urteaga González, J. L. y Nadal Piqué, F. (eds.) (2017). Historia de la cartografía urbana en España: Modelos y realizaciones. Madrid, España: Centro Nacional de Información Geográfica.

Valor Piechotta, M. (coord.) (2002). Edades de Sevilla. Hispalis, Isbiliya, Sevilla. Sevilla, España: Área de Cultura y Fiestas Mayores del Ayuntamiento de Sevilla.

Valor Piechotta, M. y Moreno Moragas, C. (coords.) (1998). Sevilla extramuros: la huella de la historia en el sector oriental de la ciudad. Sevilla, España: Universidad de Sevilla, Fundación El Monte y Ayuntamiento de Sevilla. 